\title{
Institutional Forgetting/Forgetting Institutions: Space and memory in secure forensic psychiatric care
}

\author{
Steven D. Brown, University of Leicester \\ Paula Reavey, London South Bank University
}

\section{Institutional Assemblages}

'We know the images', Michel Foucault says, 'they are familiar from all histories of psychiatry, where their function is to illustrate that happy age when madness was at last recognized and treated according to a truth to which everyone had been blind for too long' (2006: 463). He is speaking here of the 'grand asylums' that were built from the eighteenth century onwards as enormous therapeutic spaces for the containment and treatment of significant mental health issues. These new institutions replaced the former system, where mental health was conflated with poverty and criminality. Psychiatry emerges a distinct discipline in tandem with the construction of these novel institutional spaces. Patients admitted to the care provided in these secure settings, with their locked doors and fixed regimes, would find the psychological space to address their own psychological issues. But often at the cost of their present liberty, their immediate future aspirations and often their very identity.

Over the past decade, we have been involved in a number of studies that concern how mental health service users experience the spaces they inhabit, both inside and outside institutions (see McGrath, Reavey \& Brown, 2008; Brown \& Tucker, 2010; Brown, Reavey, Kanyeredzi \& Batty, 2013). An obvious starting point for such work would be around thematics of power and ritualisation, as found, for instance, in Erving Goffman's work on institutionalization. Goffman (1991) brilliantly demonstrated how patients in asylums were disciplined via the systematic removal of their past identities (e.g. through symbolic gestures, such as the removal of personal items and clothing) to ensure maximum compliance with hospital procedures. The subjects of Goffman's research become 'docile bodies' through their induction into the 'degradation rituals' of the asylum, separated from the world outside and their former life by the literal and symbolic enclosure of space. 
However, the kinds of institutions that Goffman studied are now historical and cultural relics across much of Western Europe and North America. A programme of closure of the 'grand asylums' gathered pace from 1970s onwards, replaced by a system of long term outpatient care in the community, coupled with emergency shortterm inpatient care, usually co-located in general hospital grounds. The problem for many mental health service users is typically not that of getting out of secure care, but instead of getting into the mental health system at all. Michel Foucault gave us many of the conceptual tools to understand how the initial enclosure of mental health or, as he puts it, the 'great confinement' was enacted, along with its place within the generalized 'penal archipelago' of the eighteenth and nineteenth century (Foucault, $1976 ; 2006)^{1}$. We still await the thinker bold enough to give us a similarly farreaching account of the decline of the 'total institution' of the grand asylum.

In the absence of such a work, we can focus instead on the transformation of the 'social topology' of mental health. The term comes from the joint work of Annemarie Mol and John Law (1994). Their longstanding project has been to seek alternative descriptions of how spatial and temporal relations are assembled in the domain that can be loosely termed 'the social' 2 . Drawing upon ideas from topology, Mol \& Law argue that "the social' does not exist as a single spatial type. Rather, it performs several kinds of space in which different 'operations' take place' (Mol \& Law, 1994: 643). Social space does not come in one topological form, they claim, despite the traditional tendency of social scientists to think in terms of distinct regions and boundaries. In Goffman's work, for instance, the inside space of 'total institutions', such as psychiatric units or prisons, is closed off from the outside world in a way that allows for the control and management of relations between patients/prisoners and staff. The social world one finds within the total institution is analytically treated as

\footnotetext{
${ }^{1}$ It is worth noting that Foucault's historical account of the rise of the asylum is not uncontroversial, although this is perhaps of less interest than the account of power and subjectivity to which it gives rise.

2 This can only be a loose term since as Actor-Network Theory (ANT) has demonstrated in some considerable detail, there are no firm distinctions to be drawn between domains such as 'society', 'science', 'technology', 'nature' etc. This argument is most closely associated with Bruno Latour's work (e.g. Latour, 2013; 2005; 1993).
} 
utterly different from that outside. However, Foucault's study of the social architecture of power that emerges in what he calls the 'disciplinary societies' of the eighteenth and nineteenth centuries, shows that the purpose of incarceration, whether it be in prisons, hospitals or factories, is not to exclude inmates from broader relations (Foucault, 2003; 2007). What these institutions do instead is create new patterns of circulation of people, knowledge and capital between institutions. Discipline is a distributed system of power for managing movement rather than enclosing and holding still ${ }^{3}$.

Foucault's work led to a shift away from treating institutions as monolithic spaces of control towards a more nuanced account of assembling relations amongst heterogeneous sets of materials. This approach, broadly informed by the work of Foucault's contemporary, Gilles Deleuze, views institutions as assemblages (or 'agencements') that perform a work of drawing together (i.e. 'assembling', 'connecting together') spatial and temporal relations. Jane Bennett offers a useful summary:

Assemblages are ad hoc groupings of diverse elements, of vibrant materials of all sorts. Assemblages are living throbbing confederations that are able to function despite the persistent presence of energies that confound them from within. They have uneven topographies, because some of the points at which the various affects and bodies cross paths are more heavily trafficked than others, and so power is not distributed equally across its surface. Assemblages are not governed by any central head: no one materiality or type of material has sufficient competence to determine consistently the trajectory or impact of the group. The effects generated by an assemblage are, rather, emergent properties, emergent in their ability to make something happen ... is distinct from the sum of the vital force of each materiality considered along. Each member and proto-member of the assemblage has a certain vital force, but there is also an effectivity proper to the grouping as such: an agency of the assemblage. And precisely because each member-actant maintains an

\footnotetext{
${ }^{3}$ See Salter, 2013 for an argument that relates Foucault's work to the current 'mobilities' paradigm in social science.
} 
energetic pulse slightly 'off' from that of the assemblage, an assemblage is never a stolid block but an open-ended collective, a 'non-totalizable sum'. An assemblage thus not only has a distinctive history of formation but a finite life span (2010: 23-24)

We can tease apart the dense set of ideas that are contained here. Instead of asking for the formal basis upon which institutions rest (i.e. law, beliefs, cultural conventions), it is the heterogeneity of the 'diverse elements' that make an assemblage that is of interest. Assemblages are gatherings of persons, materials and codes that cohere loosely rather than interlock. The elements do not synthesise into some form of superordinate or supra-individual entity. Internal differences and tensions remain fundamental to how the assemblage operates. Moreover, there is rarely a singular regulatory process that governs the assemblage - multiple and contradictory cognitive and affective codings are at work simultaneously. As a consequence, relations of power and governance within the assemblage are not straightforward. In practice, the overarching purpose and goals of the assemblage may not be entirely clear, and may instead emerge through its own activity. In this way the historical emergence and 'life' of a given assemblage requires a very singular analysis.

This way of approaching institutions and other forms of social structure has gathered pace considerably over the past decade (see DeLanda, 2006; Phillips, 2006; Anderson \& MacFarlane, 2011). Bu in order to see the virtue in its application to secure forensic psychiatric institutions, we will have to rewrite Bennett's extract a little:

The secure unit is complex and changeable arrangement of medical, legal and governmental practices, mixing together nurses, former prisoners, airlock doors, depot injections, charts, televisions, plastic cutlery, cigarettes, staff rotas, sunlight, and bedrooms littered with belongings. The unit can be a lively place, especially during times when patients arrive on transfer from prison, where the contradictory demands of care and containment can rub up against one another uneasily, notably around issues like personal relationships. The space of the unit is difficult to properly gauge, since patients may be allowed off the ward into the general hospital grounds and to make community visits; there is a distinctly different 'feel' to the common areas and the individual 
bedrooms, reflecting the various kinds of activities that are possible in each.

Whilst there is a clear management structure, it is difficult to know where exactly the unit sits - are we in the prison system, the medical system or somewhere else entirely? This partial ambiguity allows for the emergence of practices and relationships that are particular to the unit, some of which would be difficult to understand if one approached the unit as either purely a space of containment or purely a space of treatment. Everyone and everything that enters the unit lends something specific, from East African nurses to long-term service users to middle-class psychiatrists mixed together in this space; this unique confluence of identities and experiences seems integral to how the place seems to 'work' as whole. Yet precisely because it is such a mixture, the unit seems to be rather porous - people, practices and objects seem to be displaced, to move through and across the extended space of the unit in unpredictable ways. The place has its own history, one that seems to be written and rewritten on an almost daily basis.

If Goffman found rituals and practices in 'total institutions' designed to divide and enclose social space, what one finds in institutional 'assemblages' is instead a complex arranging of spatial and temporal relations that connects together prisons, hospitals and local communities. Both staff and patients are put into patterns of circulation that reconfigure their life space. Bodies are arranged in the shifting space of the unit (which can narrow to locked wards or dilate to include the general hospital, other units and community visits). This work of arranging serves to surface a diverse range of propositions, some of which are contradictory - 'she is doing better', 'he remains a danger to himself', 'right now things are more settled'. The stretching and compressing or 'churn' of relations creates a changeable affective atmosphere.

In this chapter, we will explore how this folding of space and time is experienced by patients in secure care. The material we discuss here comes from a study of medium secure forensic mental health ward in a part of Greater London ${ }^{4}$. This is a ward for

\footnotetext{
4 Forensic psychiatric units are graded from 'low' through 'medium' to 'secure'. Secure means that patients are not able to leave the unit without the agreement of clinicians. Whilst there are only three high security units in England - Broadmoor, Ashworth and Rampton - medium and low secure units are maintained by every
} 
where forensic psychiatric patients are detained or 'sectioned' for treatment under the Mental Health Act. These patients have committed an 'index offence' for which they have either been arrested, remanded or found guilty (Department of Health, 1983). Some patients have been transferred from prison, others have been referred directly to the unit. Detention on the ward typically lasts at least two years, and for around 1 in 5 patients can be for between 5 to 10 years, and in some cases for between 10 to 20 years or longer.

\section{Folding Space and Time on the Ward}

To understand how the reconfiguring of life space occurs in the institutional assemblage, it is important to explore the affordances of the physical setting of the ward. The invariant qualities of the setting constitute very particular kinds of potential experiences. In the unit where we conducted research, there are four wards, which housed patients at various stages of their treatment and rehabilitation. There are also a series of corridors, many leading to 'airlock' spaces, where one set of door is required to be locked before the next may be opened. Each ward has its own specific category of patients, ranging from acute patients who were severely distressed (mostly deemed psychotic), through to patients on a rehabilitation ward who appeared calm, and were mostly unsupervised. All patients are medicated, usually administered via depot injection $^{5}$. On the rehabilitation ward, access to the community is gradually introduced, until some patients are permitted to leave the unit unaccompanied for several hours and even days at a time. Some of the patients we interviewed, therefore, had a less than clear delineation between hospital and community spaces.

On the whole though, most patients are confined to a locked ward space, which had two or three communal spaces, including a television room, games room, bathrooms

NHS trust. Medium units are typically co-located with general hospitals. Around two thirds of units use single-sex wards, but mixed-sexed wards are found in the remaining third (Fleming, 2007). The work we have conducted has been on singlesex wards.

${ }^{5} \mathrm{~A}$ depot injection is a method of delivering anti-psychotic medication that is administered directly into large muscle tissue, such as the buttocks. They are slow releasing and typically last up to six weeks 
and communal dining space. In the centre of these communal spaces is a nurse's station, surrounded by glass and a locked door. To attract the attention of nurses outside of regular scheduled interaction, patients knock on the locked door or windows (this can be a source of routine conflict). For the majority of the time, nurses sit at computer stations, typing up notes on patient conduct and commenting on the presence or absence of 'symptoms' of mental illness. On the whole, there is little physical interaction between nursing staff and patients, except at points of disruption/crisis. To escape the daily low-level irritations of communal living in this relatively restricted environment, patients often spend time in their bedrooms, where they have access to music systems and occasionally a television linked up to a DVD player. Despite such means of retreat, however, staff have continual access to patients, and are able to 'look in' to bedrooms even late at night using window shutters controlled from the outside to enable regular observations ${ }^{6}$.

Together, these physical features of the setting help to constitute the social topology of the ward. They do this by shaping what actions are permitted, and which become difficult to perform or impossible. For example, there is no place on the ward where a patient can be properly alone, without the possibility of observation, even whilst sleeping. The design of the unit clearly communicates propositions of containment and observation through locks, observational windows, bolted down chairs and tables (to prevent them being used as weapons). There is very little here that might offer a sense of 'homeliness' - no carpets or lamps or even toilet seats (which are removed, due to risk of self harm). Bedrooms are designed to remove anything that might serve as potential ligature points. Windows open only the slightest amount. There are no sharp corners on any of the furniture. It is difficult to mount posters or photographs on a bedroom wall because pins and blu-tack ${ }^{7}$ are banned in case of swallowing. The environment clearly proposes to patients that the principal concern of the unit is the management of risk.

The discourse of risk animates all relationships on the unit. A common experience is for patients to be kept waiting until appropriate numbers of staff are available to

6 See Brown, Reavey, Kanyedrezi \& Batty (2014) for more details.

${ }^{7}$ Blu-tack is a trademarked name for low adhesion putty 
supervise activities such as being taken for an appointment with a $\mathrm{GP}^{8}$. Particular times on the unit, such as meal times, are anticipated as being potential 'flashpoints'. Staff tend to be especially vigilant at these times, and are prepared to intervene in minor disputes over portion size or availability of particular meals, before they flare up in significant conflict. However, the concern with risk also results in the emergence of unexpected practices. Since 2008, smoking has been banned in all National Health Service (NHS) buildings in England, including forensic psychiatric units. But the ban does not apply to prisons, from where many patients have been transferred ${ }^{9}$. This creates a dilemma for staff. The risks of having to manage the cravings of upset smokers is seen to outweigh those of organizing informal supervised 'smoking breaks' outside the ward. Yet as this falls at the margins of common practice in the NHS, it falls to the on-duty nursing staff to unofficially timetable these escorted breaks. The calculation of risk affords novel interaction as well as constraining routine interaction.

Staff and patients alike experience the social topology of the unit as having a distinct affective atmosphere. For example, the acoustics of the ward means that sound is accentuated in the areas where bedrooms are located. The relative quiet of the bedroom space is regularly punctuated by the sound of the clinking keys which staff are obliged to have attached to their belts. Noise is also a key sign that staff monitor to gauge the collective mood of patients - if the ward is either too quiet or too noisy, trouble is likely to be brewing. The desired atmosphere of the ward is one that is 'settled'. This translates as stability amongst the patient population (i.e. few new transfers), a relative absence of conflict between patients and with staff, and minimal displays of distress by individual patients. A similar language is inculcated amongst patients to describe their own psychological states. Being 'well' is what one ought to aspire towards. Contrary to the usual sense of the term, 'wellness' here means the ability to self-manage one's own distress rather than an absence of 'symptoms'. Being

\footnotetext{
${ }^{8}$ A General Practitioner (GP) is a non-specialist medical doctor. Patients have appointments with GPs for routine health issues, along with appointments with their consulting psychiatrists and clinical psychologists.

${ }^{9}$ The ban on smoking on secure units is one major reason why some patients say they would actually prefer to be in prison. It is a practical and symbolic marker of relative lack of autonomy on the unit compared to the penal system.
} 
able to display wellness is an important step towards being considered as in recovery, and hence closer to a review of one's section.

What is striking about the way that wellness is performed on the unit is that is does not require reference to the patient's past experiences before they entered the unit. Whilst staff are certainly aware of the nature of the index offence that resulted in a patient being placed their current section, alongside their 'history' with the psychiatric and legal system, this is not deemed to be relevant to establishing wellness. What matters is how the patient has managed himself or herself since the moment when they entered the unit. Patients are not required to demonstrate a coming to terms with the index offence and the life circumstances that surrounded it, nor are they asked to reflect on the specific factors that may have contributed to them being given a formal psychiatric diagnosis. It is in this sense that the unit enacts a form of 'institutional forgetting'. Life space is compressed to what happens on admission and what follows during the course of the patient's section. Anything prior to that is not a primary matter of concern in the institutional project of managing 'settled' wards of 'well' patients.

If life space is compressed by the social topology of the unit, then it also complexified in a range of ways. Despite the clear physical barriers on wards, life space does not map onto Euclidean or metric space, the relations through which patients feel and act cut across temporal and spatial remoteness. Take, for example, the relations between staff who administer psychotropic medication and patients. Medication is dispensed using two major techniques. The first is dispensing medication to be taken orally. Traditionally, this involved patients forming a queue on the ward to receive their specific batch of medication, which they would then swallow under the watchful gaze of nursing staff. However, the development of depot injections has rendered the interaction around medication as both more and less personal at the same time. To receive medication via this method, patients must partially expose their buttocks to a staff member, who delivers a deep-muscle injection. Once performed, there is no further need for staff to monitor the behaviour of the patient for compliance with their medication, as the medication remains active in the patient's body for a number of weeks. Whilst depot injections greatly reduce the need for the physical presence of staff, we might say that the relationship of compliance remains active, mediated 
through the patient's very veins. The relations between staff and patients are enacted through direct intervention at the biochemical level, as well as through ongoing physical interaction.

The spatial relations that are constituted by the ward seem to unfold in all manner of different directions. Despite the locked doors, various features of the world beyond the physical limits of wards are part of the relationships on the unit. One patient, for example, explained how his interactions with staff could be severely affected by what he perceived to be the member of staff's "domestic troubles". Whatever was occurring in the space of the staff member's home was felt to travel with them to the ward, shaping the relations that were enacted there. Another patient felt the inequalities between themselves and staff intensely. They described how staff were able to leave the ward at the close of each day, to return to 'a wife or husband, and find relief and support there', whereas patients had no such alternate space in which to retreat.

The boundaries of the unit are porous; the supposed 'outside' is continuously being folded into relations on the ward. When patients reach the point in their recovery where they are allowed to make community visits, their movements back and forth from the ward create perturbations. At a mundane level, staff are concerned with the possibility of contraband items, such as illicit drugs, pornography or mobile phones, being brought back into the unit. But in terms of the affective atmosphere of the ward, patients also bring back stories of their experiences whilst back in the community social occasions, sexual encounters, what it is to have autonomy again. These stories become threaded into relations between patients, who are able to vicariously place themselves outside the locked doors of the unit through the sharing of the experiences of community visits.

The examples so far suggest that the life spaces of patients expand beyond the physical limits of the unit, but only in a relatively limited way into local communities. But if we consider the diverse mixture of elements that are brought together in the institutional assemblage, it begins to appear that the churn of relations has far greater reach. Many of the nursing staff working on these particular wards are migrants from East and West Africa, who have brought their skills and background to working in the 
NHS. The effects of migration, movements between societies, the conflicts and accommodations involved in working across different social and cultural settings, can enter into relations on the ward. Conversely, many of the psychiatrists and other clinicians working on the unit come from a class and social background that is significantly removed from that of the patients. There are a variety of historical and cultural experiences that are all in play together here, acting to deform and reshape the social topology of the unit. These can come together in ways that have significant effects on the lives of patients. Black men, for example, especially those with larger body sizes, appear to be treated as presenting greater risks than other patients, which is reflected in calculations about medication levels. Female patients relationships with male patients are viewed almost entirely from the perspective of possible predation and exploitation by staff (See Brown, Reavey, Kanyeredzi \& Batty, 2014).

The unit itself also has a history. One can see the changing patterns of practice around mental health care written into the very shape of the building. Older wards tend to be more cramped - 'rabbit runs' - with a focus of maximizing the amount of bed space and keeping all non-essential facilities off the ward itself. Newer wards reflect the priorities of the 'care in the community' policy, where secure psychiatric care is seen as a short-term last resort option. Contemporary ward designs tend to place greater emphasis on communal spaces, including outdoor spaces, in order to foster the kind of social integration required during the transition back into living in the community. Moreover, secure psychiatric units tend to have a well-embedded reputation and historical character amongst the local communities in which they are sited. These are places that engender curiosity, humour and fear in equal measures. Patients may themselves have spoken of or joked about the site long before being transferred to the unit on a section.

At the heart, then, of the secure unit is the paradox of an assemblage that has a distinctive historical formation and which draws together highly diverse spatial and temporal relations, but which is, nevertheless, focused on discounting and actively forgetting the past experiences of the patients around which it is constituted. The space of the ward operates somewhat outside of conventional temporal systems. On one hand, experiences on the ward are regimented by standard institutional time, such as meals, medical consultations and ward rounds, washing and perhaps the occasional 
group activity. And yet, time on the ward is indeterminate, to such an extent that patients feel as if time passes without any clear demarcation, where literally, the ward is simply a time of containment, which they move through in a structureless fashion, without a clear sense of when this perpetual presenteeism will end ${ }^{10}$.

\section{Categories of Thought}

In How Institutions Think, the anthropologist Mary Douglas offers an account of how the forms of social solidarity that we think of as 'institutions' emerge and develop. She points in particular to the way in which institutions draw upon systems of classification, or ways of naming and ordering the world, over which they then claim ownership. Often this is done, she claims, by using an overarching analogy with some aspect of the natural world, such that the classification system comes to seem timeless and immutable. Ideas that fit this framework tend to be preserved; those that do not are rendered problematic and disruptive. Douglas goes on to assert that:

Any institution ... starts to control the memory of its members; it causes them to forget experiences incompatible with its righteous image, and it brings to their minds events which sustain the view of nature that is complementary to itself. It provides the categories of their thought, sets the terms for selfknowledge, and fixes identities (Douglas, 1987: 112)

To become a member of an institution - either willingly or unwillingly - is to find oneself bound, to some degree, by the categories and ways of thinking that it enshrines. The identity that is subsequently conferred upon persons by virtue of their membership shapes their self-knowledge. One becomes the sort of person who is made over in the image of the institution. One starts to think as the institution thinks. Past experiences are then reconstructed and organized to fit with the patterns that are validated by the institutional framework. And one active forgets those experiences that are 'incompatible with its righteous image'. In this way, institutions 'take charge' of memory.

10In the UK, patients who enter an NHS facility through the criminal justice system can be detained indefinitely, through regular reviews of their section, if they are deemed to be a risk to society, due to their mental state 
Douglas' account puts us on the way to understanding both how and why the institutional assemblage requires patients to engage in active forgetting. One aspect of the assemblage is the set of codes and categories it deploys to make sense of what it does. These are the diagnostic categories of forensic mental health, such as Personality Disorder (PD) and Schizophrenia. Critical scholars of mental health practices such as Richard Bentall and Mary Boyle have shown in painstaking detail exactly how these kinds of categories are culturally and historical contingent, and the nature of the kind of work which goes into sustaining them, rather than exploring alternative accounts of mental health and distress ${ }^{11}$. But in relation to the unit, it is important to recognize that for practical purposes these kinds of categories are taken to have an independent, natural existence that serves to ground the work that goes on in the wards. As evidence of this, it is common to hear patients referred to purely in terms of diagnostic labels - a 'PD patient', 'Psychosis patient' etc.

These categories form the basis for how the institution thinks and are the source of membership for patients. If one cannot be labeled by this classification system, then really one has no place on the unit (with the likely outcome of being transferred back into the prison system). It is a peculiar feature of how these diagnostic categories are defined that they require little reference to autobiographical memory. For example, a diagnosis of Personality Disorder can be made based on current feelings (e.g. fear of being left alone), recent behaviour (e.g. personally damaging impulsive activities) and general self-perception (e.g. disconnected from one's thoughts). Very little of this requires the person being assessed to offer an account of specific past experiences. In fact, when we interviewed patients they often commented that this was one of the first occasions when they had been invited to discuss their life experiences. In the following, one of the researchers $(\mathrm{R})$ asks the patient $(\mathrm{P})$ their feelings about the interview they had just completed:

$\mathrm{R} \quad$ How do you think the interview went?

$\mathrm{P} \quad$ Yeah. Yeah, I think the first bit was the hardest thing

\footnotetext{
11 See Bentall 2004 and Boyle 1990. For an overview of how one might systematically think alternative perspectives in mental health, including service user perspectives, see Cromby, Harper \& Reavey, 2013
} 
R Yeah (laughs)

P Like tell me about yourself, I've never really done that before (laughs)... I wasn't used to that, no-one's ever asked me.

It can seem extraordinary to people unfamiliar with mental health assessment that 'talking about yourself' is not central to the practice. But this is because the categories which structure how this particular institution thinks are concerned with patterns of thought, feeling and action which are considered to have a clear, independent existence that transcends any particular occasion - that is to say, it is not necessary to hear about any life event in particular in order to make a diagnosis (see Cromby, Harper \& Reavey, 2013). Moreover, in forensic psychiatric care, the recent behaviour of the person being assessed is already a matter of (criminal) record. The institution does not need to hear the life story of the prospective patient to make a decision on whether to admit them or not.

If past life experiences are not particularly relevant during the process of initial assessment, then they become even less so once the person has been admitted as a patient to the unit. Many patients in forensic psychiatric care can recall very difficult histories, often involving experiences of neglect and physical and sexual abuse. Addressing such issues is not part of the remit of the unit, whose primary concern is rather with the stabilization of symptoms of poor mental health. In part, this is because the working institutional assumption is that the kinds of mental issues that are seen in forensic psychiatric care are life-long conditions, which can be managed but are never 'cure-able' in the usual sense of that term. This can be a source of distress to patients, who do perceive their experiences as being directly relevant to their current mental well-being and self-esteem:

Sometimes you tell them things [the staff] and they don't give a shit about it [the patient here is referring to an alleged sexual assault by a staff member]. It's probably like being on trial. You have told one of the doctors, the junior doctors, and she just said to me, I can't really do nothing about it because it was in the past, in the past and we are here now. 
The major practices and 'categories of thought' operating within the unit aim at stabilisation of patients within the present, rather than facilitating access to the past or establishing its present relevance. What is of course absent from this current project of stabilisation is its continually mediation by the temporal and spatial complexities we have discussed so far. For example, the space of the ward which serves as the environment for patients, folds within it relations from beyond its own physical boundaries, including the home spaces and intimate relations of the staff. Whilst considerations of what has happened outside the unit are not deemed relevant in understanding a patient's current 'wellness', patients claim that matter such as their confidence, behaviour and self-esteem are all affected by this folding-in of outside relations:

Um (...) I suppose looking at it maybe they've [i.e. staff members] had a fight at home, or they've had an argument with their wife, or whatever, they haven't paid the bill or whatever, they've had financial difficulty. They bring their emotions onto the ward, and they take it out on the patients, you know, you know they like they shout at you and talk to you like you're an animal, you're a third class person ... it makes you, you feel like, it makes you feel like you're unworthy, you're not worth anything, you know. If you're trying to build up confidence because that's how you've felt before, you're trying to build your self-esteem and stay focused and try to make a life for yourself, you know, it's just makes you feel despondent.

Topologically speaking, even though the home spaces of staff are remote, they are still present and formative in the affective landscape of the patient (and staff). The project of 'wellness', which involves being able to display control over things such as self-esteem, is interrupted by relations on the ward, which are in turn shaped by relational vectors from the 'outside'. It seems that whilst temporal and spatial relations beyond the ward are deemed irrelevant for assessing wellness, they are continuously entering into the life space of patients via their interaction with staff. Or put slightly differently, the institutional assemblage is porous and leaky with regard to its management of relations. But this cannot formally acknowledged, creating a paradox that is not lost upon patients: you want me to be well by focusing only on the 
present but you ignore how that present is being continuously pushed and pulled by forces from the outside.

\section{Corporeal Transformations}

If one aspect of the institutional assemblage is the deployment of categories of thought that constitute a 'regime of forgetting' focused on maintaining 'wellness', then the other is the organization of bodies and corporeal relations on the unit. What we see here is the way that patient bodies become groupings within the institututional assemblage that are mediated by psychotropic medication. Patients on the unit are normally required to take a range of medication, ranging from 'typical' and 'atypical' anti-psychotic treatment to drugs for depression and anxiety, along with other medication for managing side-effects and physical symptoms ${ }^{12}$. Medication can be experienced in wide range of ways, depending on the individual concerned. Antipsychotics, for example, may lessen feelings of paranoia or hearing voices, but they can also bring about restlessness, sleepiness, felt slowness of thinking, sexual dysfunction, dizziness and excess saliva.

In this way, the body can act as site of transformation, where new ways of relating to oneself are constituted. We call these novel self-relations Psychologically Modified Experiences (PMEs). Using an analogy with Genetically Modified Organisms (GMOs), we have argued elsewhere that forensic psychiatric care reformulates experiences from the existing 'experience-ecology'. For example, prior to entering care, patients may have had varied and diverse experiences around sexuality. But on the unit itself, patients are encouraged to view sexuality as either something that must be entirely 'left behind' or as inherently risky and potentially comprising to 'wellness'. This reshaping of what sexuality is and what it can mean is further compounded by anti-psychotic medication, which can leave patients feeling estranged from themselves as sexual beings - as one of the patients put it 'this place has amputated my sexuality’ (Brown, Reavey, Kanyeredzi \& Batty, 2014: 250). Patients then come to experience a very different version of sexuality from that which they have known before. PMEs are constituted as novel experiences which combine

12 Clozapine is the dominant form of anti-psychotic medication used in secure care 
elements that are both highly concrete (e.g. sexual feelings, bodily sensations) and highly abstract (e.g. discourses of risk and predation, the need to present oneself as 'well'). Having been adopted during the course of secure care, PMEs remain with patients as part of their efforts to demonstrate 'wellness' once they return to community based care.

As an institutional assemblage, the unit both organises bodies, placing them into particular temporal and spatial relations with one another, and organises through bodies, by acting directly on the feelings and experiences of patients, in part through direct intervention in their biological states. How the patient moves through the ward and hospital space is marked by both the invariant structures of the physical space, and through the corporeal affordances created by the medication. The felt sense of detachment from the past that patients experience comes as much from this organizing of bodies as it does from discursive practices of discounting prior experience. There can be, of course, direct cognitive impacts of medication that may impair memory. For instance, we have found in our work that 'settled' patients taking antipsychotics are rarely able to sustain a conversation in a research interview beyond 30-45 minutes. However, our particular interest here is on the experiential and felt sense of the past being literally displaced via the operations of medication upon the body and subsequent enactments in time and space. One of the major ways in which a separation between the past and present is created and sustained is through literal transformations in the shape and functioning of the body. Patients reported this with some regularity:

When I was on Clozapine, I put on a lot of weight. And the thing is I hate about Clozapine is that people really like just go on and on about it. But it's not all that you know. With me, it had such bad side effects ... My heart beated really fast. It was like 130. You know, I was always drooling. I was tired a lot. You know, I slept a lot. I put on a lot of weight, you know. I went from size 12 to 22 and I'm still a 22 and I'm trying to lose weight.

Changes to the body were largely reported to be unpleasant and anxiety inducing, physiologically (rapid heart-beat) and psychologically (tiredness and weight gain). Female patients expressed particular concern about weight gain. Entry into the unit 
involved not just a loss of liberty, but also a loss of control over one's body-image. Gaining significant amounts of weight acted as a very visible marker of the transformation to one's identity brought about by being sectioned. The past is here directly indexed to one's physical appearance before being transferred, and the lack of any subsequent significant development during time on the ward - 'I went from a size 12 to 22 and I'm still a 22'. Many patients commented on their 'past self' being lost to a newly modified self, brought about by changes to the body, and subsequently mood. This was sometimes thought to be irreversible and hence problematic. But it could also be recuperated by taking ownership of the discourse of 'wellness', such as in the following:

but I must admit the medication has helped me over the years, just calmed me down a lot ... my moods stabilized as well with that. But I will say I am not the same person I was 22 years ago. I've changed completely. And the medication has helped me, you know, it has helped me really.

Here ideas of being 'stable' and 'settled' are used to reformulate the loss of former self. Being 'not the same person' is presented as a positive transformation.

Medication also heightens the stretching of temporal relations on the ward. Patients described a slowing down of time in general, due to fatigue. This can be clearly seen when one enters a ward on the unit. Patients tend to move slowly, often without clear purpose, and may at times simply lie on the floor. Many describe an alteration in their perception of time, feeling as though their 'body clock' no longer operated as it once did. As one patient remarked:

I sleep during the day, and am awake during the night. My body doesn't know what it's doing. The way I was before doesn't resemble what I'm doing now at all. It's weird.

If the invariant physical structure of the ward itself offers few opportunities to structure the day, beyond occasional routine appointments, then the effects of medication act further complexify the sense of time passing. For the most part, patients are left to make their own choices about where they wish to spend the day in 
the relatively restricted space of the ward. Typically this makes for an irregular pattern of sleeping, interacting with others, eating and watching television. Some patients describe this as retreating between their bedroom and communal areas, with no real comfort to be found in either space - you stay with others until it becomes too much, you be by yourself until you can handle it no longer. Time unfolds through this alternation without purpose.

The discourse of 'wellness' and 'settled' wards finds its counterpart in an ordering of patients as docile bodies, whose movements and patterns of activity are fairly stable. For patients, this means that control over their own bodies comes to be seen as emblematic of finding a way beyond the immediate boundaries of the unit. For example, in the following one of the researchers asks a patient how she manages to deal with the interactional difficulties of life on the ward:

R You said ... over here you found it quite difficult because you remember certain things that people said that were prejudiced. But it does sound quite difficult ... how do you cope with that difficulty? ... What sort of things do you focus on?

P Well, getting out, losing weight, growing my hair, just having a future, like things I want to do in the future.

The 'future' the patient envisages here involves a return to a past physical state. For this woman, growing her hair back to its original state and losing the weight she had gained on medication signified a prior sense of self, and a felt sense of agency. In this way, connecting with both the past and the future seems to directly mediated by taking control of embodiment - if I can get back to how I used to look, I will become again the person I was before I came here. The way out of the regime of forgetting is through the self-relation to the body. But it is not easy to find the means to be able to work on this self-relation, since the experiences that pre-date admission have been overlaid with PMEs. In the next extract, a patient describes how his relationship to medication and his body has changed during her time on the unit:

$\mathrm{P} \quad$ [the medication means] I'm tired all the time

$\mathrm{R} \quad \mathrm{Mm}$ 
P So, I don't know, if its normal, but I guess it is normal but that's one thing like, that I don't really like it all really... Because I used to be much more active than I am now.

R Hm, mm

$\mathrm{P} \quad$ And mm, I just haven't got the strength you need to like do exercise and stuff like that you know.

$\mathrm{R} \quad$ God and did you talk about these side effects with your Doctor?

P Yeah, I mentioned it a few times ... Now here's the funny thing about it, is that I, I, I could just laugh about it up until about 3 years ago, I said this about 4 years 'cos I've been away for a long time you know ... I said to him, I used to go to the gym ... then after that I'd go swimming, and skipping and he's like 'you've past your peak', and I'm like (young) ... Do I don't know, I, I I I feel really frustrated if I couldn't get out and do stuff, so I just smoke instead.

In this reporting of a doctor-patient interaction, the patient talks about his past active self being replaced by a tired and inactive version. For the patient, this is entirely attributable to the side-effects of medication, since, as he puts, 'I'm like young'. The comment he reports the doctor as making - 'you've past your peak' - is then double edged. On the one hand, it could be interpreted as simple reference to the patient's age, since as he himself acknowledges, 'I've been away for a long time'. But it seems more likely that this comment points to a shared knowledge between doctor and patient that ageing works differently in secure care. Long-term anti-psychotic medication can accelerate the development of many physical markers usually associated with ageing, such as high blood pressure, stiffness and shaking, diabetes. Patients in secure care can also develop problems with the teeth and gums, through lack of care and dietary issues. When this is taken together with weight gain and a general lack of exercise, patients can both look and feel 'past their prime' at a far earlier chronological age than would be expected. So whilst patients are suspended in a present that allows little reference to past or future, their bodies may be marking out time at an excessive rate. Small wonder that when confronted with this realization that he will never be able to return to both the body and the self of the man he was before secure care, this patient decides to 'just smoke instead'. 
Some patients make direct links between these kinds of transformation to the body through medication and being unable to remember what their body can do at basic level, in terms of activities such as eating, moving and being sexual. This results in a changing relationship to self:

P They want to ... you've got ... Yeah because I'm on medication, I can't sleep, yeah, you don't feel like eating, you don't feel like going to the gym, you don't feel like exercising, you know, but that's not what it should be like, you - you look after yourself, for the girls and you know that, but we don't have that ... you can't do that no more ... we've got that - you don't have, you don't understand what sex is anymore.

R Right ... Could you tell me a bit more about that, that you don't understand what sex is. What you mean you sort of forget about it, or?

P Yeah

R Right, OK

P It's like a (a drug) Yeah ... making you work a lot of the time, work a lot of the time, you know ... And they can't see, yeah. Obviously don't understand, but it changes, it does change the way you see contact, you know, it changes, your personality changes. So it changes after that - a long time off them and it changes ... Because I don't really have thoughts (sexual), you know what I mean, you know, that, I can't appreciate it any more

As this patient describes it, sexuality was previously integral to how he related to his own body because 'you look after yourself, for the girls'. Once the possibility of sexual expression has been removed following his transfer to the secure care, he begins to neglect his body, a process that is intensified by the de-motivating effects of medication. This leaves him the situation of feeling displaced in relation to his own embodiment - 'you don't understand what sex is anymore'. Sexuality belongs with the person he was before. In his current state, he no longer experiences sexual thoughts, he has become estranged from that physical aspect of what he was. Another patient describes this process of corporeal displacement directly as 'forgetting': 
R Okay (...) So have you been able to continue feeling and being sexual while you've been here?

P No ... Well, I I don't plan, I don't really think of sex a lot, I don't even know if I remember how to do it, I've forgotten how to do it

If sexuality belongs to a past that is neither relevant nor entirely thinkable in terms of the discursive practices and ordering of bodies on the unit, then it may, perhaps, be ceded to a future that lies after the ending of the section, on return to the community. But as this patient describes it, the displacement or forgetting of that aspect of one's embodiment makes it difficult to imagine how one could resume life as a sexual being - 'I've forgotten how to do it'. The discounting of past experiences and feelings here seems to set up a future where even if the patient does leave the ward, they will be, in a sense, stuck in the 'presentism' that it inculcates. It is this sense of the irreversible nature of the transformations that occur in terms of one's relation to oneself that seems most troubling to patients:

I would say this place has amputated my sexuality. Definitely, it's - it's not my home, it's not - it's not a free environment and (...) it's a - it's so anti-life. I just don't even think about sexuality in here and I grieve over that quite a lot. And (...) I try and cope with this place on its own terms, you know and whatever it has to offer me I will engage with. So and try to make it a reality, its own reality but I still can't feel human enough to be a sexual being in this environment.

We read this extract as a description of what can happen to the life space of the patient when it absorbed into the ordering practices of the ward. This patient focuses in particular on the lack of private space and restricted movement. She uses the phrase 'anti-life' to sum up her feeling. Everything here seems corrosive of the vitality of living. She has become estranged from the feelings and experiences that made her the person she was. She is now a body without a past and, apparently, with little sense of the future.

\section{Conclusion}


The provision of secure psychiatric care has undergone dramatic changes in the past half-century. The 'grand asylums' which Foucault saw as means by which 'madness' became enclosed in the disciplinary architecture of modernity have been replaced by more supple and distributed networks of care and concern, where secure environments constitute only a small part. We have used the notion of assemblage to explore the heterogeneous composition of these very particular institutional settings. Our focus has been on the emergent modes of ordering time and space that occur on secure forensic psychiatric unit. Here, temporal as well as spatial folding occurs, such that patients are caught up in what amounts to a 'regime of forgetting', where 'wellness' and stabilization of mental health are paramount.

And yet, like all assemblages, there are tensions and discontinuities in how the unit works. The end point of secure care is reached when the patient is deemed suitably settled to be able to return to the community. But the corporeal transformations that are required to adapt to life on the unit may leave patients singularly unsuited to community care. The relation to oneself as a sexual being, for example, is interrupted by both medication and by the overarching discourse of risk. Sexuality is transformed into what we have termed a 'psychologically modified experience' - a form of experience that is shaped by the discursive practices of psychiatry. It is not simply the case that patients are left bearing the marks of institutional life. It is rather that the institution disrupts the capacity to make coherence between a past and a future life at a vital, corporeal level of experience.

This invites an immediate response: so what? Secure forensic psychiatric units are scarcely the only institutions to mould and shape those who find themselves within them. Prisons, hospitals, schools and factories arguably do much the same. Why should life on the secure unit be any different? The answer is that historically this institutional assemblage provisionally exists merely as a site of experimentation for techniques that will render its continuing existence as redundant. There is, within both psychiatric discourse and contemporary public policy literally no future for secure psychiatric care. It remains in place only as a stop-gap until more effective methods of community care can be evolved. So here is the paradox. An institution that serves as a vehicle for de-institutionalization but which operates, at a deep corporeal and 
psychological level, as a route to re-institutionalization. Now that is something that really demands our critical engagement and reflection.

\section{References}

Anderson, B. and C. McFarlane, C. 2011. Assemblage and geography. Area 43(2): $124-127$

Bennett, J. 2010. Vibrant Matter: A Political Ecology of Things. Durham: Duke University Press.

Bentall, R. 2004. Madness Explained: Psychosis and Human Nature. London: Penguin.

Boyle, M. 2002. Schizophrenia: A Scientific Delusion? London: Routledge.

Brown, S.D. and I. Tucker 2010. Eff the ineffable: Affect, somatic management and mental health service users. In The Affect Theory Reader, eds. M. Gregg and G. Seigworth. Durham: Duke University Press, pp. 229-249.

Brown, S.D., P. Reavey, A. Kanyeredzi and R. Batty 2014. Transformations of self and sexuality: psychiatric inpatients accounts of sexuality and relationships. Health 18: 240-260.

Cromby, J., D. Harper and P. Reavey, P 2013. Psychology, Mental Health and distress. Basingstoke: Palgrave.

DeLanda, M. 2006. A New Philosophy of Society: Assemblage Theory and Social Complexity. London: Continuum.

Douglas, M. 1987. How Institutions Think. London: Routledge.

Goffman, E. 1991. Asylums: Essays on the Social Situation of Mental Patients and Other Inmates. London: Penguin.

Fleming, N. 2007. One in six hospitals treat in mixed wards. The Telegraph, 10 May.

Foucault, M. 1976. Discipline and Punish: The Birth of the Prison. London: Penguin.

Foucault, M. 2003. Society Must be Defended: Lectures at the Collège de France, 1975-1976. London: Penguin.

Foucault, M. 2006. History of Madness. London: Routledge.

Foucault, M. 2007. Security, Territory, Population: Lectures at the Collège de France, 1977-1978. New York: Picador. 
McGrath, L., P. Reavey and S.D. Brown 2008. The scenes and spaces of anxiety: Embodied expressions of distress in public and private fora. Emotion, Space \& Society 1(1): 56-64. DOI: 10.1016/j.emospa.2008.08.003

Mol, A. and J. Law, J 1994. Regions, Networks and Fluids: Anaemia and Social. Social Studies of Science, 24(4): 641-671

Phillips, J. 2006. Agencement/Assemblage. Theory Culture Society 23: 108-109. Salter, M.B. 2013. To Make Move and Let Stop: Mobility and the Assemblage of Circulation. Mobilities 8(1): 7-19.

\begin{abstract}
Secure forensic psychiatric care can be approached as an 'institutional assemblage'. In place of the old 'grand asylums', modern units are emergent spaces of care and security that consist of heterogeneous and contradictory sets of elements. Secure units enact a folding of time and space, despite their porous boundaries and extensions into the community. Patients live a 'suspended life' where their past experiences are deemed irrelevant to the stabilization of their current condition. This institutes a 'regime of forgetting' based around recoding experience into the categories of thought of psychiatric discourse. The outcome is a changed self-relation in the form of a corporeal transformation, where the ability to create coherence between past and future experience is disrupted.
\end{abstract}

\title{
Keywords
}

Assemblage; Foucault; Deleuze; Social topology; Psychiatric discourse; Psychologically modified experience; Forensic psychiatric care 